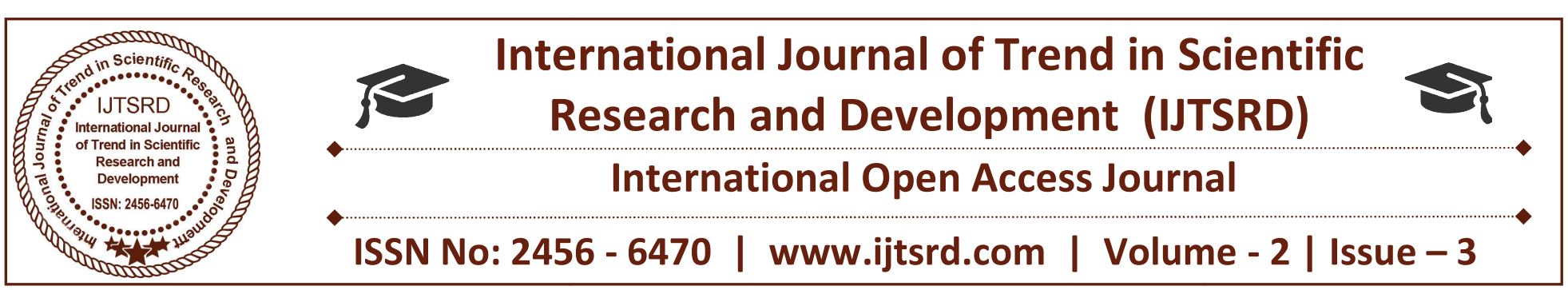

\title{
Design and Fabrication of Mechanical Maize Decobber
}

\author{
Prof M. Suresh Kumar, T. A. Ajay Chakravarthi, N. Arun Kumar, S. Hariprasaath \\ Department of Mechanical Engineering, \\ Bannari Amman Institute of Technology, Sathyamangalam, Erode, Tamil Nadu, India
}

\begin{abstract}
Maize, known in many English-speaking countries as corn, is a grain domesticated by indigenous people in prehistoric times. The Aztecs and Mayans cultivated it in numerous varieties throughout central and southern Mexico, to cook or grind. The crop spread throughout America and later around the $1250 \mathrm{BC}$ it spread to all corners of the region. Any significant or dense populations in the region developed a great trade network based on surplus and varieties of maize crops. After European contact with the Americas in the late 15 th and early 16 th centuries, explorers and traders carried maize back to Europe and introduced it to other countries through trade. Maize spread to the rest of the world due to its popularity and ability to grow in diverse climates. The existing methods of corn de-husking in agriculture industry consist of breaking the grains by hand or by using large machinery for deseeding, both of which are not effective for a developing economy like India where farmers have little money for investment. Hence there is a need for an innovative idea or product that is feasible, safe, cost effective and productive for the Indian farmer.
\end{abstract}

\section{INTRODUCTION}

Maize is, after wheat and rice, the most important cereal grain in the world, providing nutrients for humans and animals and serving as a basic raw material for the production of starch, oil and protein, alcoholic beverages, food sweeteners and, more recently, fuel. It is because of that importance of maize that it's processing and preservation to an optimum condition must be analysed. The major steps involved in the processing of maize are harvesting, drying, de-husking, shelling, storing, and milling. For

the rural farmers to maximize profit from their maize, appropriate technology that suites their needs must be used. The processing of agricultural products like maize into quality forms not only prolongs the useful life of these products, but increases the net profit farmers make from mechanization technologies such products. One of the most important processing operations done to bring out the quality of maize is shelling or threshing of maize.

\section{PROBLEM IDENTIFICATION}

In our country, most of the farmers shell corn by mainly three methods namely shelling cob grain by hand; hand operated corn Sheller and beating by stick method were carried for removing corn kernel from the cob. The Corn shelling was designed and built to improve the standards of living of people living in villages of developing countries. There are several electrical operated Corn shelling machines for mass shelling. Mostly farmers used to take their unshelled Corns to such industries were they get their final product that is shelled Corn and then they used to sell this product to the market. This incurred the cost of transportation between farms to machine industry increase the cost of product. Most of contractor used to give less cost for unshelled Corn and they got the profit of shelled Corns. The problems are similar and manifold. Part of the solution to these problems lies in the evolution of an Intermediate Technology i.e. Low capital, labor-intensive, locally based. This concept of a technology more appropriate to the needs of developing countries can be applied equally well to agricultural mechanization. The problems of underdevelopment are particularly acute in the rural areas of countries, where the poorest people live and where agricultural underproduction and migration has 
most effect. This affects the livelihood of the farmers. In order to make the transportation of the cultivated maize to the process of decobbing, the farmers have to spend more than the current cultivating and selling cost. So in order to overcome the problem, a handy and more powerful, low cost maize decobbing machine has to be fabricated and manufactured. This helps the farmers to decob their maize by themselves without being transported to other areas for decobbing. Hence the cost for processing of the cash crop is reduced and the farmer gets the required cost for his maize with the help of automatic maize decobbing machine.

\section{DESIGN}

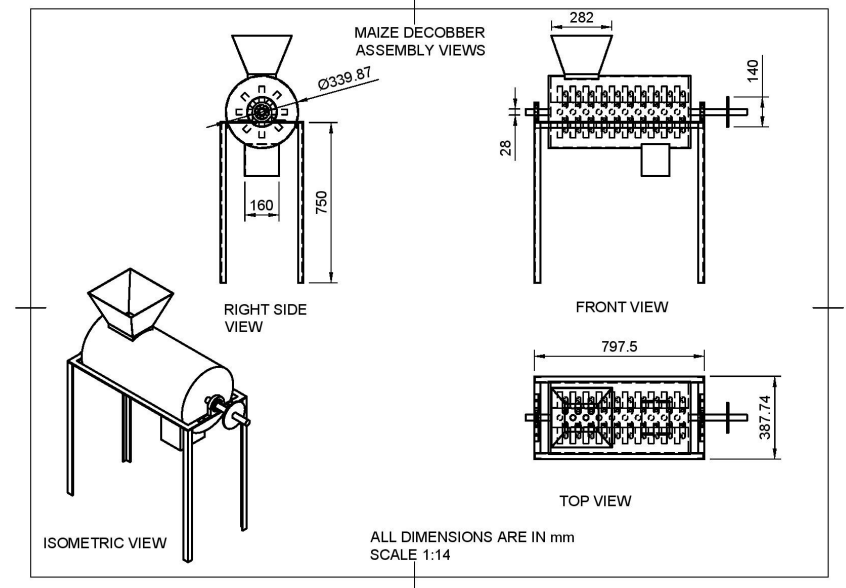

Fig 1:Isometric view of overall design

\section{DETAILED DRAWING OF COMPONENTS}

\section{Frame:}

The frame is the structural portion which erects the machine above the ground and support it.

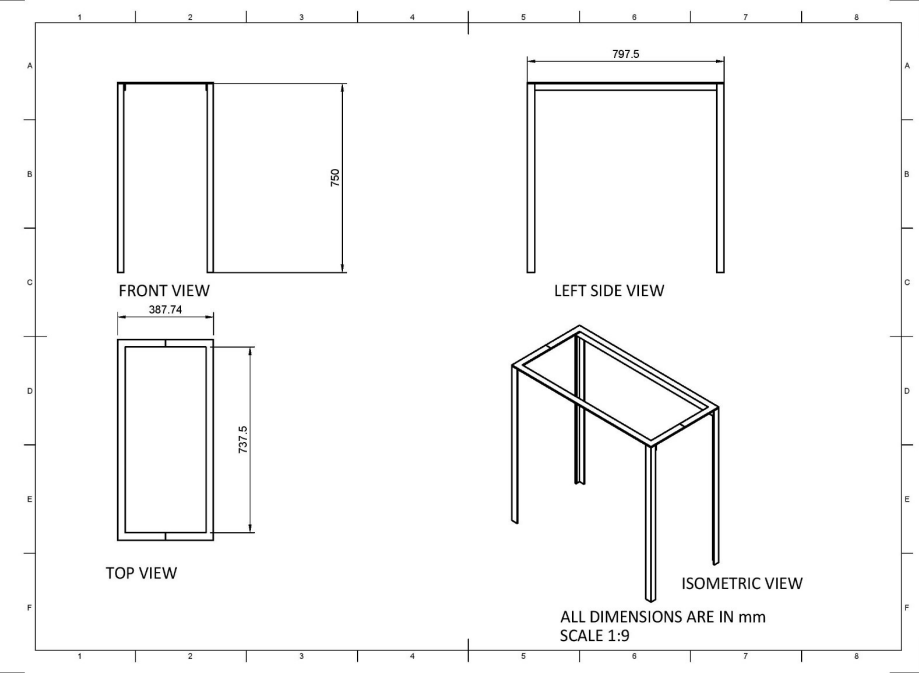

Shelling cylinder:

The shelling cylinder is cylinder with spikes arranged on it. This is the component which removes the cob from maize. The spikes are arranged in alternate rows and columns. This will prevent the maize from getting stuck in between the spikes of the cylinder.

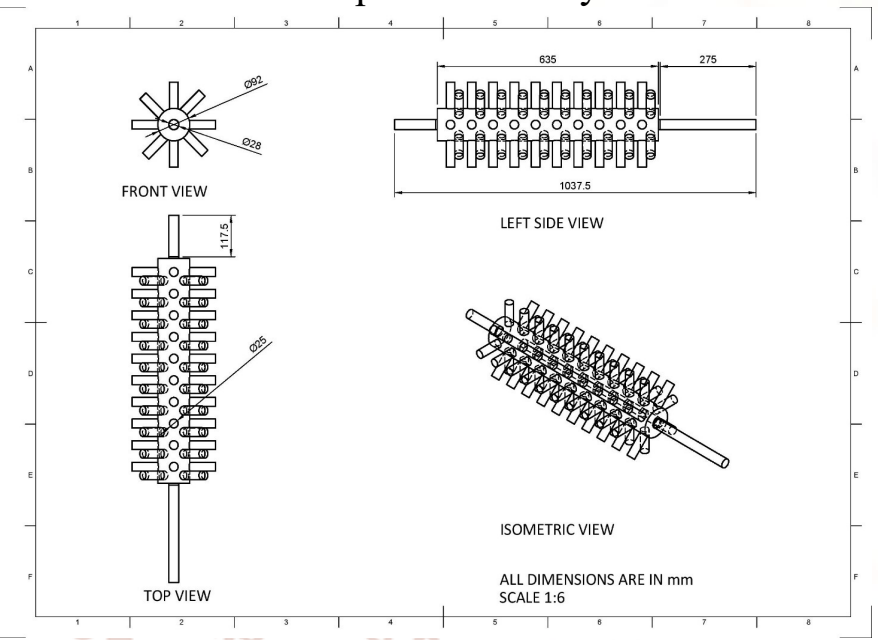

\section{Bearing:}

Bearing is used to fix the shelling cylinder with the structural framework. This enables the shelling cylinder to rotate while fixed on the frame.

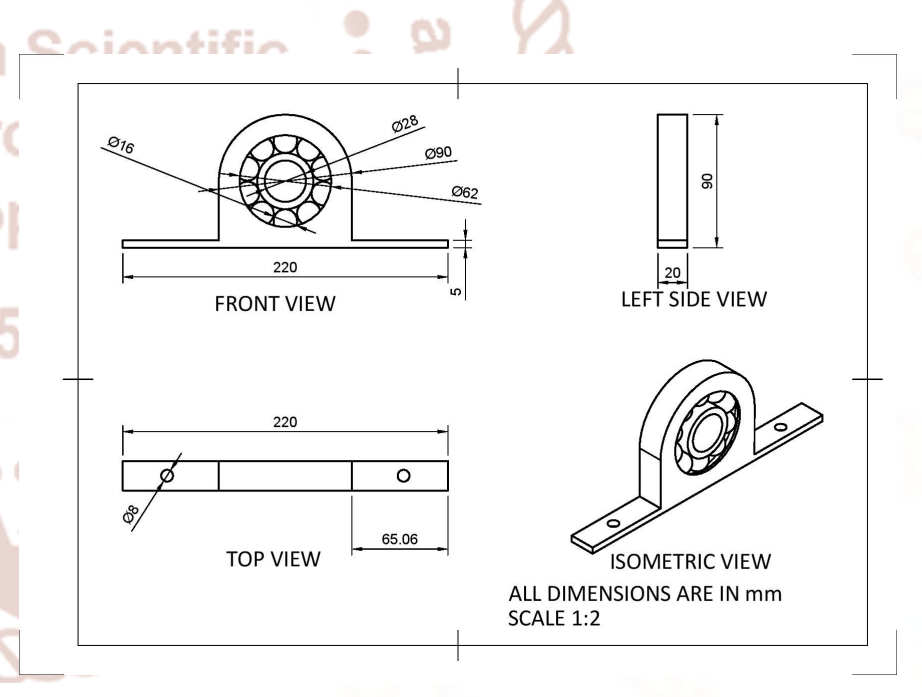

\section{Body Cover:}

The body cover encloses the shelling cylinder. It protects the user from the damage that may occur during the operation of the machine. 


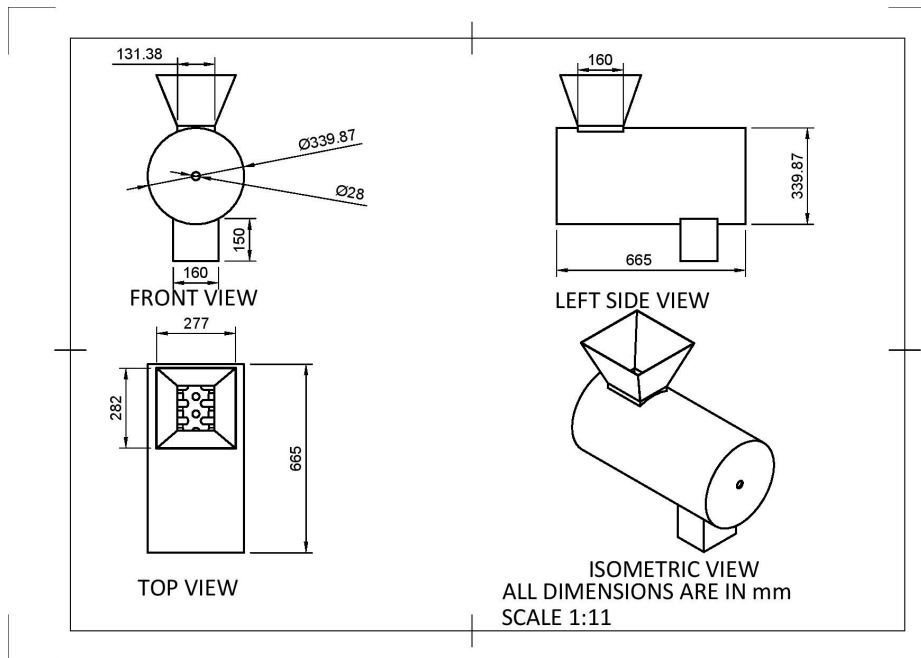

\section{ADVANTAGE}

- It reduces labour power

- Required less time

- Easy operation

- Production capacity is increased in case of industry usage

\section{CONCLUSION}

Thus a machine at low cost to deseed the corn grains from corn kernel is designed and its operation is discussed.

\section{Pulley:}

\section{REFERENCES}

It is a wheel with groove on it. It is used to transmit the electric power from the motor to the shelling cylinder.

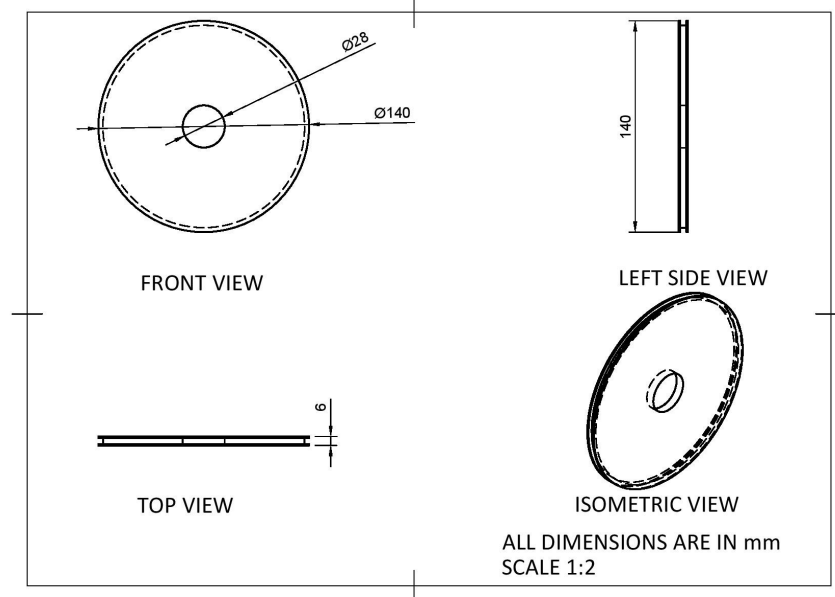

\section{OPERATION}

The electric motor provides the primary motion required to power the machine. The motion and torque are transmitted via pulleys, belt and bearings to the shaft carrying the spikes. The de-cobbing spikes. The whole maize (together with the cobs) are introduced into the machine through the inlet hopper. They reach the rotating spikes inside the de-cobbing barrel by gravity. The spikes give continuous impact force on the whole maize, thereby removing the grains and chaff. Because the spikes are arranged in a spiral form, the whole maize moves along the length of the barrel in the forward direction until they reach the cob exit spout. Before the whole maize reaches this point, almost all the grains (seeds) are removed thereby letting the cob go out of the machine clean. Due to the impact of the spikes some of the cobs may be broken, though both broken and whole exit through the exit spout.
1) IJSRD - International Journal for Scientific Research \& Development| Vol. 3, Issue 04, 2015 | ISSN (online): 2321-0613, Crank Operated Maize Sheller Girish Karikatti1 Jangali Satish J2 Anjali Kathani3 Roopa Lokeshwar4 Sameer Sattur5 1,2,3,4,5Department of Industrial \& Production Engineering 1,2,3,4,5BVB College of Engineering \& Technology, Hubli, Karnataka, India.

2) IJIRST /nternational Journal for Innovative Research in Science \& Technology| Volume 2 | Issue 01 | June 2015. Anirudha G. Darudkar Dr. C. C. Handa PG Student Head of the Department, Department of Computer Science, Department of Mechanical Engineering,K.D.K.C.E Nagpur, India K.D.K.C.E Nagpur, India.

3) 3. Design and Performance Evaluation of a Corn De-Cobbing and Separating Machine Oriaku E.C, Agulanna C.N, Nwannewuihe H.U, Onwukwe M.C And Adiele, I.D Engineering Research; Development and Production (ERDP) Department. Projects Development Institute, (PRODA) Emene, Enugu.

4) 4. Design, Construction And Performance Analysis Of A Maize Thresher For Rural Dweller, J.N. Nwakairea, B.O. Ugwuishiwub, C.J. Ohagwuc Department of Agric. \& Bioresources Engineering, University of Nigeria, Nsukka, Nigeria.

5) 5. Manually-powered continuous-flow maizesheller, S.O. Nkakini a, M.J. Ayotamuno a, G.P.D. Maeba a, S.O.T. Ogaji b, ${ }^{*}$, S.D. Probert b a Agricultural and Environmental Engineering Department, Rivers State University of Science and Technology, Port Harcourt. P.M.B. 5080, Rivers State, Nigeria b School of Engineering, Cranfield University, Bedfordshire MK43 OAL, United Kingdom. 